\title{
Effectiveness of an intermediate care hospital on readmissions, mortality, activities of daily living and use of health care services among hospitalized adults aged 60 years and older-a controlled observational study
}

\author{
Unni Dahl ${ }^{1,2^{*}}$, Aslak Steinsbekk ${ }^{1}$ and Roar Johnsen ${ }^{1}$
}

\begin{abstract}
Background: Intermediate care is a health care model developed to optimize the coordination of health care services and functional independence. In Central Norway, an intermediate care hospital (ICH) was established in a municipality to improve hospital discharge and follow-up among elderly patients with chronic conditions and comprehensive care needs. The aim of this study was to investigate the effectiveness of hospital discharges to a municipality with an $\mathrm{ICH}$ compared to discharges to a municipality without an $\mathrm{ICH}$.

Methods: This was a non-randomized controlled observational study of hospitalized patients aged 60 years and older from two municipalities. Patients $(n=328)$ admitted to a general hospital from February 2010 through September 2011 were included in the study and followed for 12 months. The data were analyzed using descriptive statistics, analysis of covariance (ANCOVA) and Cox proportional hazard regression.

Results: Each patient discharged from the general hospital to the municipality with an $\mathrm{ICH}$ had a shorter length of stay and used on average $4.2(p=0.046)$ fewer hospital days during 1 year compared to patients from the municipality without an $\mathrm{ICH}$. Otherwise, no statistical significant differences were found between the municipalities in terms of hospital readmissions, admissions, mortality, activities of daily living, primary health care utilization or total care days. A post hoc analysis of patients discharged to the $\mathrm{ICH}$ compared to the municipality without an ICH, showed that the $\mathrm{ICH}$ patients were older and frailer, but the outcome was similar to the main analysis.

Conclusions: Having an ICH in the municipality facilitated shorter length of hospital stay and kept the risk of readmissions, mortality and post-hospitalization care needs at the same level as without an $\mathrm{ICH}$.
\end{abstract}

\section{Background}

Many health care systems worldwide are facing challenges due to an increasing ageing population $[1,2]$. Currently, hospitalized elderly patients with chronic diseases are cared for in a system largely organized for acute care $[3,4]$. This approach is often inadequate to meet the specific needs of patients with multiple and complex health conditions. Hence, improving the chain

\footnotetext{
* Correspondence: unni.dahl@ntnu.no

'Department of Public Health and General Practice, Norwegian University of Science and Technology, Post box 8905 Medisinsk teknisk forskningssenter, 7491 Trondheim, Norway

${ }^{2}$ Central Norway Health Authority, 7500 Stjørdal, Norway
}

of care to respond to the demands of elderly patients is a key challenge [5-7].

Hospitalizations [8] and discharge [9] can provoke events that negatively affect the patient for a long time after hospitalization. Delayed discharge is associated with acute illness episodes and death [10], and elderly patients discharged from hospital with unmet functional needs have an increased risk of readmissions [11]. It has been documented that $23 \%$ of elderly patients experience an adverse event after discharge such as drug events, therapeutic errors and infections [12].

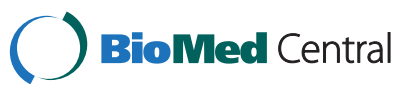

(c) 2015 Dahl et al. Open Access This article is distributed under the terms of the Creative Commons Attribution 4.0 International License (http://creativecommons.org/licenses/by/4.0/), which permits unrestricted use, distribution, and reproduction in any medium, provided you give appropriate credit to the original author(s) and the source, provide a link to the Creative Commons license, and indicate if changes were made. The Creative Commons Public Domain Dedication waiver (http://creativecommons.org/publicdomain/zero/1.0/) applies to the data made available in this article, unless otherwise stated. 
In response to these health care challenges, interventions and models to improve the coordination of services and safety during hospital discharge have been introduced [13-15]. Intermediate care is one such health care model. It is an umbrella term for a rehabilitationtype arrangement between primary and secondary care that is intended to reduce unnecessary hospital use and optimize functional independence [16]. The term has its origins in the UK [17], however similar models have been developed in several countries to improve and manage changing health care needs [18-20].

Intermediate care services range from nurse-led units to services delivered in the patients' own home [21]. Due to the different types of intermediate care, summarizing their effectiveness based on evidence is challenging [22]. Studies of intermediate care have shown that the services can enable patients to regain abilities in daily living, decrease readmissions and reduce mortality [19, 23-25]. Still, the reported effects of intermediate care services are inconsistent $[21,26,27]$. In addition to the aforementioned outcomes, addressing the integration of intermediate care into the wider health care system is recommended for further investigation $[18,28,29]$.

We previously studied the impact of hospital discharges to an intermediate care hospital ( $\mathrm{ICH}$ ) that was a part of the primary health care system and found that the $\mathrm{ICH}$ reduced the length of hospital stays for the municipality inhabitants', but had only minor influence on the primary health care consumption [30]. However, that study used aggregated, not individual-linked data, from primary and secondary health care. The aim of this study was to investigate the effectiveness of hospital discharges of patients aged 60 years and older to a municipality with an $\mathrm{ICH}$ compared to discharges to a municipality without an $\mathrm{ICH}$ on readmissions, mortality, activities of daily living (ADL) and health care use during 1 year follow-up.

\section{Methods}

\section{Study design and ethics}

This was a non-randomized controlled observational study including patients from two municipalities admitted to the same local general hospital in Central Norway (Fig. 1). The intervention municipality established an intermediate care hospital (ICH) in 2007. The other municipality (without an intermediate care hospital) was the control. Hospitalized patients from the two municipalities were included in the study from February 2010 through September 2011. The end of follow-up was October 2012. This evaluation is reported in accordance with the Trend Statement for reporting non-randomized studies of interventions [31].

The Regional Committee for Medical Research Ethics approved the study (2009/1697a) as well as the patient

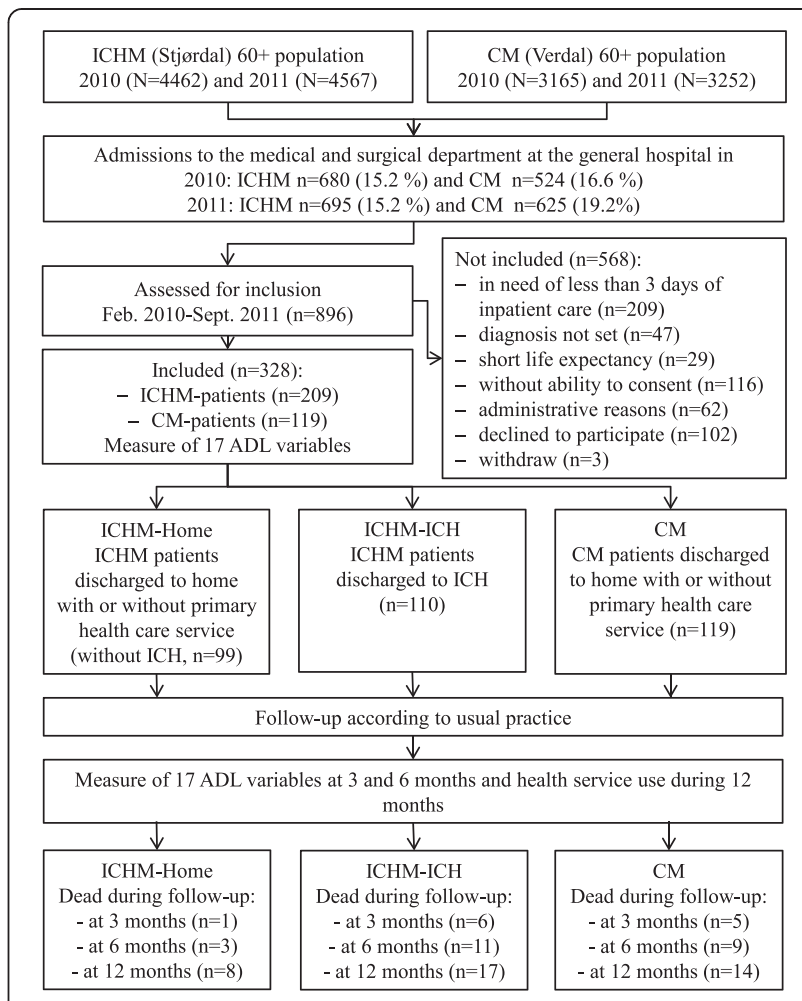

Fig. 1 Flow chart of the study. $C M=$ Comparative municipality. ICHM = Intermediate care hospital municipality. ICH = Intermediate care hospital

information and consent schemes. The participating municipalities, the ICH and the local general hospital also approved the study. Each participating patient signed a written informed consent at the general hospital prior to inclusion in the study. The study was registered in www.clinicaltrials.gov (Trial number: NCT01706744).

\section{Setting}

The Norwegian health and social care system is primarily a public system. It is organized within two main sectors; the secondary care with hospitals and specialist services on the one hand and primary health care on the other. The hospitals are state owned and organized within health enterprises managed by four regional health authorities. The municipalities are responsible for primary health care services including home care, nursing homes and general practitioners (GPs) [32].

The patients in this study resided in one of two municipalities; the Intermediate care hospital municipality (ICHM) and the Comparative municipality (CM). In 2011 the population size was 21,659 in the ICHM and 14,334 in the CM. Both municipalities are located in the catchment area of a 200-bed general hospital named "Sykehuset Levanger" within the health enterprise "Helse Nord-Trøndelag". 
The hospital admission rates from the ICHM and the CM were stable in the years before the study (2005-2009) and until the end of the follow-up (2010-2012) [30]. In 2010 and 201116.6 and $19.2 \%$ of the CM-inhabitants aged 60 years and older were admitted to the medical or surgical department of the general hospital. It was $15.2 \%$ in both years from the ICHM (Fig. 1).

In 2007, the ICHM established the ICH in collaboration with the general hospital and the regional health authorities to offload the hospital with patients ready for discharge and to improve the coordination of services [33]. The ICH is a 12-bed inpatient ward co-located with primary health care services. It is mainly staffed by nurses. Additionally, there are occupational therapists, physiotherapists and a GP during weekdays. The intermediate care is targeted at elderly patients with multiple and chronic conditions and comprehensive care needs who were discharged from the general hospital. When the patients are ready for discharge, they are admitted to the $\mathrm{ICH}$ on the same or next day. Discharge is aimed to be earlier when going to the ICH than directly to primary health care services. The ICH-staff emphasize follow-up treatment and enable as many patients as possible to return to their homes. The patients are provided with daily living aids such as walkers and crutches and the staff encourages them to practice activities of daily living (ADL) e.g. walking in the corridor, climbing stairs and socializing with other patients whilst in $\mathrm{ICH}$.

Patients from the ICHM who are not discharged to the $\mathrm{ICH}$ and patients from the comparative municipality (CM) were discharged as usual. They were hospitalized until discharge to their homes or until necessary primary health care services were available.

Health professionals' experiences of patient discharge to municipalities with and without the $\mathrm{ICH}$ have been described in a previous qualitative study [34].

\section{Participants}

The inclusion and exclusion criteria were selected to establish a group of patients who were eligible for an $\mathrm{ICH}$ stay regardless of whether an ICH was available. The inclusion criteria were patients living in the ICHM or the $\mathrm{CM}$, aged 60 years and older, admitted from their own homes to the medical or surgical department at the general hospital, assessed to be in need of in-patient care for at least 3 days after completion of the hospital diagnostics and the initial treatment and expected to return home after in-patient care. The exclusion criteria were patients without the ability to consent (due to dementia or other medical conditions) and short life expectancy.

The main comparison groups were patients from the ICHM and CM. However, the ICHM patients comprised two groups; those discharged directly from the hospital to the $\mathrm{ICH}$ and those who were discharged directly to home with or without the need for primary health care services.

\section{Data collection}

Nurses included patients during the first days of hospitalization at the general hospital (index stay). Inclusion was performed before the hospital physicians had decided where the patients should be discharged. The data were collected at the index stay and during 1 year of follow-up after hospital discharge or until death.

Information on hospital stays were collected from the general hospital's register, the university hospital's register and from the national register (Norwegian Patient Register, NPR). Stays at specialized rehabilitation centers were collected directly from the rehabilitation institutions in Central Norway and supplemented by national data from the NPR.

Data on the use of primary health care services were collected from the municipalities' own registers. The ICH stay data were collected from the $\mathrm{ICH}$ and subsequently added to the institutional primary health care stays in the ICHM.

Nurses in the general hospital and in the primary health care services were selected to measure and record 17 ADL variables at index hospital stay and at 3 and 6 months follow-up. These ADLs have been compulsorily and routinely recorded for individuals who request or are in need of primary health care services in all Norwegian municipalities since 2006 (IPLOS) [35, 36]. IPLOS is a register-based information system, used in other Norwegian studies [37, 38], that characterizes patient dependencies by the following variables: eating, dressing, personal hygiene, using the toilet, indoor and outdoor mobility, cooking, housekeeping, shopping, maintaining own health, communication, social interaction, daily decision taking, memory, behavioural control, sight and hearing. The ADL variables are used to assess the patients' need for assistance, and trained personnel perform the scoring. Each ADL is measured on a scale from one to five. A score of one means no disability; two indicates some functional challenges while three is given when the patient is in need of assistance. A score of four is used for an increased need of assistance and five means extensive need of assistance. In a hospital setting, patients do not perform all activities even if they are capable of doing so, e.g. housekeeping and cooking. Nevertheless, all patients in this study were scored according to their potential capacity to perform the activities [37]. The functional status was calculated as the mean value of all $17 \mathrm{ADL}$ variables.

Publicly available population data was collected from Statistics Norway [39].

\section{Outcome measures}

The outcomes were measured 3 months and 1 year from index hospital admission except for the proportion of 
patients with readmissions within 30 days. The functional status was measured at 3 and 6 months from the index hospital admission. Hospitalization and rehabilitation stays were taken from a national data register. Hospital admissions, hospital days and length of hospital stay included the patients' index stay. Hospital admissions were calculated as any in-patient stay (acute and elective) as well as the number of acute admissions after index hospital discharge was counted. A readmission was defined as any acute hospital admission within 30 days from a previous discharge [40] regardless if the readmission occurred during the ICH stay. For readmission incidents within 30 days during 1 year, the first subsequent readmission was counted. It then became a new admission from which a further readmission might occur [41]. Total days with institutional care comprised all in-patient stays, i.e., hospital days, institutional primary health care, $\mathrm{ICH}$, and specialized rehabilitation. Hour-based primary health care services included home care nursing, practical assistance at home, day-center visits, and other types of support to persons living at home. Institutional primary health care were short- and long-term stays in nursing homes. The ICH stays were included in the institutional primary health care in the ICHM. Mortality was measured as the number of deceased patients during 1 year of follow-up after the index hospital discharge, and number of days until death.

\section{Statistical analysis}

A comparison of the outcomes for the two municipalities (ICHM and CM) was the primary analysis. Descriptive analyses were used to describe the samples.
For categorical variables, Pearson's chi-square tests were used to identify any differences in proportions between the municipalities; Student's $t$-test was used for continuous variables. Between-group differences for readmissions, health care use and functional status were analyzed with analysis of covariance (ANCOVA). The Cox proportional hazard regression was used to estimate adjusted hazard ratios (HRs) for death. Departure from the proportional hazard assumption was evaluated by graphical procedures (log-log plots).

Patient characteristics are predictors of the use of health care services. Therefore, age, gender, number of diagnoses, functional status and having primary health care (yes/no) at the index stay were included as adjustment variables. A post hoc analysis was conducted to examine the group of patients in the ICHM discharged directly to the ICH (ICHM-ICH) to those discharged to the CM. A significance level of $5 \%(p<0.05)$ was chosen. The analysis was performed using SPSS 21.0 for Windows (IBM Corp., Armonk, NY).

\section{Results}

A total of 896 patients aged 60 years and older from the two municipalities were assessed for inclusion by the department nurses; 463 did not meet the inclusion criteria, 102 declined to participate and three patients withdrew after inclusion (Fig. 1). Consequently 328 patients were included. Two hundred and nine patients resided in the Intermediate care hospital municipality (ICHM-group). Of these, 110 were discharged directly to a stay at the intermediate care hospital (ICHM-ICH) and 99 were discharged to home (ICHM-Home). There were 119

Table 1 Baseline characteristics. Characteristics of patients aged 60 years and older from the $\mathrm{CM}^{\mathrm{a}}$ and the ICHM at index hospital stay and those in the ICHM discharged directly to the $\mathrm{ICH}(\mathrm{ICHM}-\mathrm{ICH})^{\mathrm{a}}$

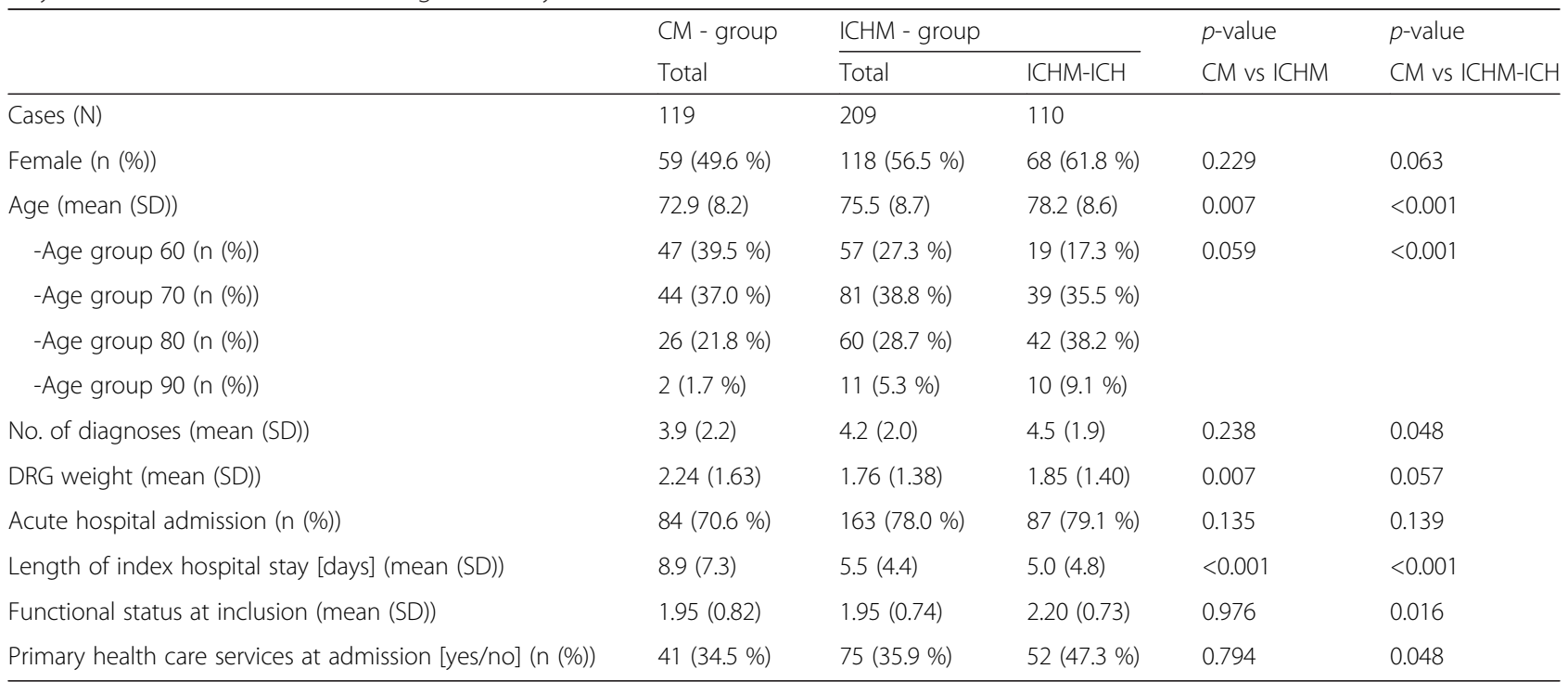


Table 2 Comparison of the ICHM-group with the CM-group. Comparison of the ICHM-group ${ }^{\mathrm{a}}$ with the $\mathrm{CM}$-group ${ }^{\mathrm{a}}$ on use of health care services and functional status during 1 year after hospitalization for patients aged 60 years and older. (CM: 119 patients. ICHM: 209 patients) ${ }^{\mathrm{d}}$

\begin{tabular}{|c|c|c|c|c|c|}
\hline Variable & Municipality & $\begin{array}{l}\text { Crude } \\
\text { mean (SD) }\end{array}$ & $\begin{array}{l}\text { Adj. mean } \\
(95 \% \mathrm{Cl})\end{array}$ & $\begin{array}{l}\text { Adj. mean diff. } \\
(95 \% \mathrm{Cl})\end{array}$ & $p$-value \\
\hline \multicolumn{6}{|l|}{ Use of hospital care } \\
\hline \multirow[t]{2}{*}{ Mean number of hospital admissions during 3 months } & CM & $1.55(1.01)$ & $1.52(1.34$ to 1.70$)$ & $-0.09(-0.31$ to 0.14$)$ & 0.446 \\
\hline & $\mathrm{ICHM}$ & $1.58(1.04)$ & $1.61(1.47$ to 1.74$)$ & & \\
\hline \multirow[t]{2}{*}{ Mean number of hospital admissions during 1 year } & CM & $2.25(2.06)$ & 2.18 (1.79 to 2.56$)$ & $-0.41(-0.89$ to 0.07$)$ & 0.092 \\
\hline & $\mathrm{ICHM}$ & $2.54(2.26)$ & 2.59 (2.30 to 2.87$)$ & & \\
\hline \multirow[t]{2}{*}{ - Acute admissions during 3 months } & $\mathrm{CM}$ & $0.40(0.87)$ & $0.38(0.23$ to 0.52$)$ & $-0.06(-0.25$ to 0.12$)$ & 0.481 \\
\hline & $\mathrm{ICHM}$ & $0.43(0.80)$ & $0.44(0.33$ to 0.55$)$ & & \\
\hline \multirow[t]{2}{*}{ - Acute admissions during 1 year } & CM & $0.92(1.97)$ & $0.86(0.52$ to 1.19$)$ & $-0.37(-0.80$ to 0.05$)$ & 0.085 \\
\hline & $\mathrm{ICHM}$ & $1.19(1.92)$ & $1.23(0.98$ to 1.48$)$ & & \\
\hline \multirow[t]{2}{*}{ Proportion of patients with readmissions within 30 days } & CM & $0.15(0.36)$ & $0.14(0.08$ to 0.20$)$ & $-0.01(-0.09$ to 0.08$)$ & 0.901 \\
\hline & $\mathrm{ICHM}$ & $0.14(0.35)$ & $0.15(0.10$ to 0.19$)$ & & \\
\hline \multirow{2}{*}{$\begin{array}{l}\text { Mean number of readmission incidents } \\
\text { (within } 30 \text { days) during } 1 \text { year }\end{array}$} & $\mathrm{CM}$ & $0.44(1.42)$ & 0.39 (0.15 to 0.63$)$ & $-0.20(-0.50$ to 0.10$)$ & 0.195 \\
\hline & $\mathrm{ICHM}$ & $0.56(1.29)$ & 0.59 (0.41 to 0.77$)$ & & \\
\hline \multirow[t]{2}{*}{ Mean number of hospital days during 3 months } & CM & $12.67(11.93)$ & 12.58 (10.83 to 14.33$)$ & 3.81 (1.61 to 6.01$)$ & 0.001 \\
\hline & $\mathrm{ICHM}$ & $8.67(8.82)$ & 8.77 (7.46 to 10.08$)$ & & \\
\hline \multirow[t]{2}{*}{ Mean number of hospital days during 1 year } & $\mathrm{CM}$ & $18.07(23.85)$ & 17.67 (14.41 to 20.94$)$ & 4.19 (0.08 to 8.31$)$ & 0.046 \\
\hline & $\mathrm{ICHM}$ & $13.15(14.82)$ & 13.48 (11.03 to 15.93$)$ & & \\
\hline \multirow[t]{2}{*}{ Mean length of hospital stay during 1 year (days) } & $\mathrm{CM}$ & $7.71(5.88)$ & 7.74 (6.88 to 8.60$)$ & 2.39 (1.31 to 3.47$)$ & $<0.001$ \\
\hline & $\mathrm{ICHM}$ & $5.35(4.31)$ & $5.36(4.71$ to 6.00$)$ & & \\
\hline \multicolumn{6}{|l|}{ Total care days } \\
\hline \multirow{2}{*}{$\begin{array}{l}\text { Mean number of total days with institutional care } \\
\text { during } 1 \text { year }\end{array}$} & $C M$ & $32.40(44.05)$ & 32.57 (25.05 to 40.08) & $1.99(-7.46$ to 11.45$)$ & 0.679 \\
\hline & $\mathrm{ICHM}$ & $30.41(42.24)$ & 30.57 (24.94 to 36.21$)$ & & \\
\hline \multicolumn{6}{|l|}{ Use of primary health care } \\
\hline \multirow{2}{*}{$\begin{array}{l}\text { Mean number of hour-based primary health care } \\
\text { service during } 3 \text { months }\end{array}$} & $C M$ & $25.72(56.60)$ & 26.38 (17.13 to 35.63$)$ & $2.49(-9.16$ to 14.13$)$ & 0.675 \\
\hline & $\mathrm{ICHM}$ & $24.03(57.95)$ & 23.89 (16.95 to 30.83$)$ & & \\
\hline \multirow{2}{*}{$\begin{array}{l}\text { Mean number of hour-based primary health care } \\
\text { service during } 1 \text { year }\end{array}$} & $\mathrm{CM}$ & $87.36(175.89)$ & 88.05 (56.28 to 119.82 ) & -0.76 ( -40.75 to 39.23$)$ & 0.970 \\
\hline & $\mathrm{ICHM}$ & $88.36(220.09)$ & 88.81 (64.98 to 112.64 ) & & \\
\hline \multirow{2}{*}{$\begin{array}{l}\text { Mean number of days in institutional primary health } \\
\text { care during } 3 \text { months }\end{array}$} & $\mathrm{CM}$ & $6.27(18.41)$ & 6.80 (4.49 to 9.12) & $0.51(-2.41$ to 3.42$)$ & 0.732 \\
\hline & $\mathrm{ICHM}$ & $6.54(10.13)$ & 6.29 (4.56 to 8.03$)$ & & \\
\hline \multirow{2}{*}{$\begin{array}{l}\text { Mean number of days in institutional primary health care } \\
\text { during } 1 \text { year }\end{array}$} & $\mathrm{CM}$ & $11.49(33.04)$ & 12.19 (6.23 to 18.15$)$ & $-1.77(-9.27$ to 5.73$)$ & 0.643 \\
\hline & $\mathrm{ICHM}$ & $14.24(34.37)$ & 13.96 (9.49 to 18.43$)$ & & \\
\hline \multirow[t]{2}{*}{ - Mean number of days in nursing home (long-term) } & CM & $1.80(13.15)$ & $1.90(-1.65$ to 5.45$)$ & $-1.10(-5.57$ to 3.37$)$ & 0.627 \\
\hline & $\mathrm{ICHM}$ & $3.03(22.07)$ & $3.00(0.34$ to 5.66$)$ & & \\
\hline \multirow[t]{2}{*}{ - Mean number of days in $\mathrm{ICH}$} & CM & $0.00(0.00)$ & $0.15(-1.55$ to 1.85$)$ & $-8.53(-10.67$ to -6.39$)$ & $<0.001$ \\
\hline & $\mathrm{ICHM}$ & $8.72(12.07)$ & 8.68 (7.41 to 9.96$)$ & & \\
\hline \multicolumn{6}{|l|}{$A D L^{c}$} \\
\hline Mean functional status at 3 months & CM & $1.51(0.52)$ & 1.53 (1.46 to 1.60$)$ & $-0.01(-0.11$ to 0.08$)$ & 0.762 \\
\hline
\end{tabular}


Table 2 Comparison of the ICHM-group with the CM-group. Comparison of the ICHM-group ${ }^{\mathrm{a}}$ with the $\mathrm{CM}^{-g}$ group $^{\mathrm{a}}$ on use of health care services and functional status during 1 year after hospitalization for patients aged 60 years and older. (CM: 119 patients. ICHM: 209 patients) ${ }^{\text {d }}$ (Continued)

\begin{tabular}{|c|c|c|c|c|c|}
\hline & $\mathrm{ICHM}$ & $1.55(0.48)$ & 1.54 (1.49 to 1.60$)$ & & \\
\hline \multirow[t]{2}{*}{ Mean functional status at 6 months } & CM & $1.52(0.56)$ & 1.53 (1.45 to 1.61$)$ & $0.00(-0.11$ to 0.10$)$ & 0.945 \\
\hline & ICHM & $1.54(0.49)$ & 1.53 (1.47 to 1.59$)$ & & \\
\hline
\end{tabular}

Analysis with ANCOVA adjusted for age, gender, number of diagnoses at index hospital stay, functional status at index hospital stay and having primary health care services at index hospital stay (yes/no)

${ }^{a}$ CM Comparative municipality, ICHM Intermediate care hospital municipality, ICH Intermediate care hospital

${ }^{\mathrm{b}}$ Mean number of total days with institutional care = In-patient stays at hospital, primary health care, ICH and specialized rehabilitation ${ }^{\mathrm{C}} \mathrm{ADL}=$ Activities of daily living assessed with IPLOS (a national registration system with 17 ADL variables)

${ }^{d}$ At index hospital stay patients with missing functional status were 1 in the CM and 1 in the ICHM. At 3 months the number of patients was six and seven, respectively and at 6 months it was eight and 18

patients discharged, as per usual practice, from the hospital to the Comparative municipality (CM-group).

\section{Baseline characteristics}

At baseline, the ICHM and CM patients were comparable with respect to gender, number of diagnoses, functional status, proportion having acute admissions and proportion receiving primary health care (Table 1 ). The CM-group was younger (mean age, 72.9 vs 75.5 years, $p=0.007$ ). The average diagnosis related group (DRG) weight was higher ( 2.24 vs 1.76 points, $p=0.007$ ) than in the ICHM-group. The index hospital stay was longer in the CM than in the ICHM ( 8.9 vs 5.5 days, $p<0.001)$.

\section{The ICHM-group versus the CM-group}

Each patient from the CM spent statistically significantly more days in the hospital during 1 year compared to patients from the ICHM (adj. mean difference within 3 months was 3.81 days, $p=0.001$; during 12 months it was 4.19 days, $p=0.046$ ) (Table 2). During 1 year of follow-up, the average length of the hospital stay was 2.39 more days per patient in the CM $(p<0.001)$.

Table 2 shows no statistical significant differences between the municipalities in the number of hospital admissions (including acute admissions) or the number of readmission incidents (within 30 days) during 1 year. Moreover, no differences were found for the proportion of patients with readmissions within 30 days. The results showed no differences in hour-based primary health care, days spent in institutional primary health care (including long-term stays in nursing homes), or in functional status. As a sensitivity analysis, the non-measured functional status for those who died within 3 and 6 months was replaced by a value of 5 (poorest functionality). This caused a small increase in the mean score of the functional status at 3 and 6 months. No difference between the groups remained. Interaction between adjustment variables (covariates) and group was checked and was not significant. In general, the adjustments decreased the hospital use in the CM (except for the length of hospital stay) and increased the use in the ICHM. For primary health care, the adjustments increased the use in the CM but decreased in the ICHM (except for hour-based primary health care during 1 year).

Comparing the total number of days with institutional care by adding up all in-patient stays at hospital, primary health care, $\mathrm{ICH}$ and specialized rehabilitation during 1 year showed no difference between the municipalities (adj. mean $\mathrm{CM}=32.6, \mathrm{ICHM}=30.6$ days per patient). Of the days spent in primary health care institutions in the ICHM, 8.7 days per patient was spent in the ICH (Table 2 and Fig. 2).

Regarding mortality, no difference was observed between patients from the CM (11.8\%) and the patients from the ICHM (12.0\%) (Table 3). There was no evidence of departure from the proportional hazards assumption.

\section{Post hoc analysis}

At baseline, the patients discharged from hospital directly to the ICH (ICHM-ICH) were 5.3 years older than the CM-group (Table 1). Gender, DRG weight and proportion with acute admissions were comparable. The

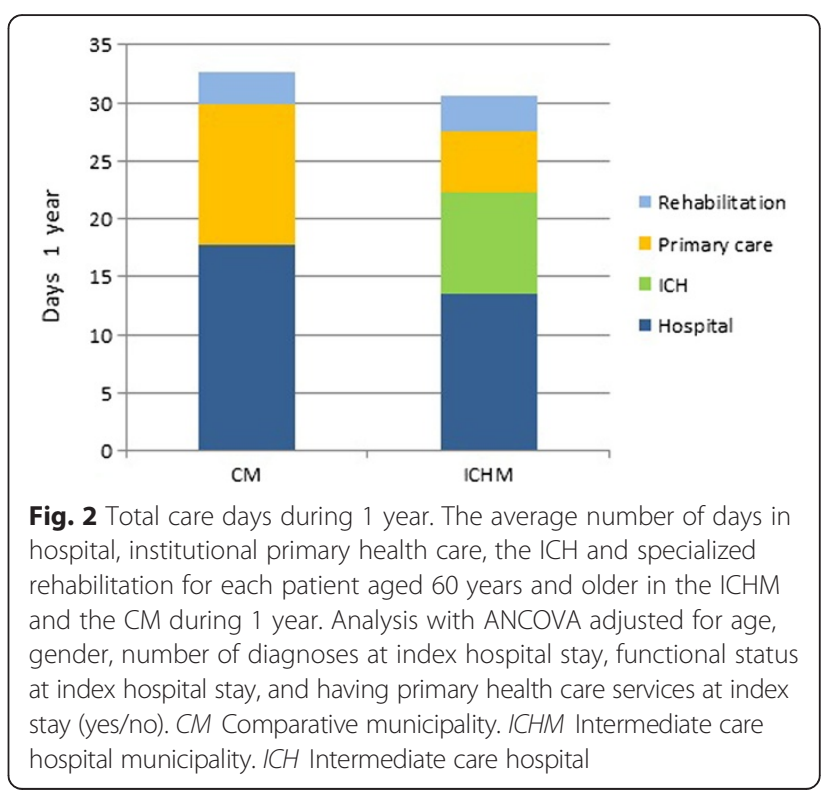


Table 3 Hazard ratios (HRs) for death 1 year after hospitalization for persons 60 years and older

\begin{tabular}{|c|c|c|c|c|c|c|}
\hline Municipality & Persondays & Deaths, n (\%) & Crude $H R^{b}$ & Adjusted $\mathrm{HR}^{c}$ & $95 \% \mathrm{Cl}^{\mathrm{C}}$ & $p$-value \\
\hline $\mathrm{CM}^{\mathrm{a}}$ & 40,429 & $14(11.8)$ & & 1 & & \\
\hline $\mathrm{ICHM}^{\mathrm{a}}$ & 71,321 & $25(12.0)$ & 1.01 & 0.93 & $0.48-1.81$ & 0.840 \\
\hline $\mathrm{ICHM}-\mathrm{ICH}^{\mathrm{a}}$ & 36,420 & $17(15.5)$ & 1.34 & 1.01 & $0.49-2.08$ & 0.981 \\
\hline
\end{tabular}

${ }^{a} \mathrm{CM}$ Comparative municipality, ICHM Intermediate care hospital municipality, ICHM-ICH Patients in the ICHM discharged directly to the ICH (Intermediate care hospital)

bunadjusted

${ }^{c}$ Adjusted for age, gender, number of diagnoses at index hospital stay, functional status at index hospital stay and having primary health care services at index stay (yes/no)

ICHM-ICH group had a higher mean number of diagnoses, worse functional status, and a higher proportion received primary health care prior to hospitalization indicating that this group was sicker and had poorer functionality, i.e., was more frail. The average index hospital stay was shorter in the ICHM-ICH group. The average length of the ICH stay after index hospital discharge was 8.3 days (data not shown in tables).

The patients in the ICHM who were discharged directly to home (ICHM-Home, data not shown in tables) had a lower DRG weight at baseline (1.65 points vs 2.24, $p=$ $0.004)$, better functional status ( 1.68 vs $1.95, p=0.006)$ and shorter length of index hospital stay (6.1 vs 8.9 days, $p<0.001)$ compared to the CM-group.

The post hoc analysis of the outcomes comparing the $\mathrm{CM}$ and the ICHM-ICH group did not substantially deviate from the results of the comparison on the municipality level presented above (Table 4). The main difference was that patients in the CM-group spent 3.75 more days $(p=0.013)$ in the hospital within 3 months than the ICHM-ICH group. During 1 year of follow-up, the average length of hospital stay was 2.33 more days per patient in the CM-group $(p=0.002)$.

There were no statistical significant differences in the number of hospital admissions, readmissions, total days with institutional care, received primary health care, functional status or mortality between the groups (Tables 3 and 4).

\section{Discussion}

The main result from this study was that patients discharged from the hospital to the municipality with an ICH (the ICHM) had 4.2 fewer hospitalization days and shorter length of stays during 12 months of follow-up than the municipality without an $\mathrm{ICH}$ (the $\mathrm{CM}$ ). No statistical significant differences in the other outcomes were observed. A post hoc analysis of those that were discharged directly to the ICH compared to the CM, gave similar findings as the main analysis.

\section{Integrating intermediate care in the chain of care}

The main finding here is comparable to a previous cohort study of all hospitalized patients aged 60 years and older residing in the ICHM and the CM from 2008 through 2012 [30]. In both studies, the patients in the ICHM used fewer hospital days.

Preventing prolonged hospital stays, strengthening primary health care and improving coordination of services are prominent goals of the Norwegian health policy [20]. The first goal was met in this study because patients in the municipality with the ICH spent fewer days in hospital. Nevertheless, studies from different countries have described how difficult it is to move patients smoothly through the chain of care due to collaboration challenges $[42,43]$ and lack of integration of intermediate care with the whole care system $[18,28]$. Findings in the current and a previous qualitative study in the ICHM and CM [34] are, however, more in line with recommendations to improve coordination of discharges for patients with complex care needs $[6,13]$. It seems reasonable to explain the lower use of hospital days in the ICHM by the health personnel's shared goal of preventing prolonged hospital stays by facilitating early and timely hospital discharges to the ICH [34].

In accordance with the target group of the ICH (elderly patients in need of follow-up care), this study confirms that the patients discharged directly to the $\mathrm{ICH}$ were the oldest with the poorest functionality, highest number of diagnoses and most in need of primary health care. One could assume that this group of patients, that was more frail than the average of the ICHM-group would need longer hospital stays. Still, the number of days in hospital for the patients discharged directly to the $\mathrm{ICH}$ was similar to patients in the ICHM-group. This suggested that the ICH helped reduce the hospital utilization for frail patients.

During the 1 year follow-up, the number of days in hospital was $31 \%$ higher in the CM (4.2 days) than in the ICHM. The average length of hospital stays per patient in the CM was $45 \%$ (2.4 days) longer. The number of days spent in institutional primary health care was similar in the municipalities even when this included the stays in the $\mathrm{ICH}$, which comprised $61 \%$ of all primary health care days in the ICHM. Also, utilization of hourbased care was similar in the municipalities. Hence, early discharges did not influence the utilization of primary health care services in the ICHM compared to the CM. This confirms previous qualitative findings in which $\mathrm{ICH}$ was used as a discharge unit in the chain of care 
Table 4 Post hoc analysis. Comparison of the ICHM-ICH group with the CM-group. Comparison of the ICHM-ICH with the $\mathrm{CM}_{\text {-group }}{ }^{\mathrm{a}}$ on use of health care services and functional status during one year after hospitalization for patients aged 60 years and older. (CM: 119 patients. ICHM-ICH: 110 patients) ${ }^{d}$

\begin{tabular}{|c|c|c|c|c|c|}
\hline Variable & Municipality & $\begin{array}{l}\text { Crude } \\
\text { mean (SD) }\end{array}$ & Adj. mean $(95 \% \mathrm{Cl})$ & Adj. mean diff. (95 \% Cl) & $p$-value \\
\hline \multicolumn{6}{|l|}{ Use of hospital care } \\
\hline \multirow[t]{2}{*}{ Mean number of hospital admissions during 3 months } & CM & $1.55(1.01)$ & $1.53(1.35$ to 1.72$)$ & $-0.05(-0.32$ to 0.22$)$ & 0.720 \\
\hline & $\mathrm{ICHM}-\mathrm{ICH}$ & $1.56(1.03)$ & 1.58 (1.39 to 1.78$)$ & & \\
\hline \multirow[t]{2}{*}{ Mean number of hospital admissions during 1 year } & CM & $2.25(2.06)$ & 2.26 (1.88 to 2.63$)$ & $-0.19(-0.74$ to 0.37$)$ & 0.512 \\
\hline & $\mathrm{ICHM}-\mathrm{ICH}$ & $2.45(2.11)$ & 2.44 (2.05 to 2.83$)$ & & \\
\hline \multirow[t]{2}{*}{ - Acute admissions during 3 months } & CM & $0.40(0.87)$ & $0.41(0.25$ to 0.56$)$ & $-0.02(-0.25$ to 0.20$)$ & 0.839 \\
\hline & $\mathrm{ICHM}-\mathrm{ICH}$ & $0.44(0.81)$ & $0.43(0.27$ to 0.59$)$ & & \\
\hline \multirow[t]{2}{*}{ - Acute admissions during 1 year } & CM & $0.92(1.97)$ & 0.96 (0.61 to 1.30$)$ & $-0.20(-0.70$ to 0.31$)$ & 0.449 \\
\hline & $\mathrm{ICHM}-\mathrm{ICH}$ & $1.20(1.85)$ & $1.15(0.80$ to 1.51$)$ & & \\
\hline \multirow[t]{2}{*}{ Proportion of patients with readmissions within 30 days } & CM & $0.15(0.36)$ & 0.15 (0.09 to 0.22$)$ & $0.03(-0.07$ to 0.12$)$ & 0.586 \\
\hline & $\mathrm{ICHM}-\mathrm{ICH}$ & $0.14(0.34)$ & $0.13(0.06$ to 0.19$)$ & & \\
\hline \multirow{2}{*}{$\begin{array}{l}\text { Mean number of readmission incidents (within } 30 \text { days) } \\
\text { during } 1 \text { year }\end{array}$} & $\mathrm{CM}$ & $0.44(1.42)$ & $0.43(0.18$ to 0.69$)$ & $-0.16(-0.54$ to 0.22$)$ & 0.419 \\
\hline & $\mathrm{ICHM}-\mathrm{ICH}$ & $0.59(1.36)$ & 0.59 (0.32 to 0.86$)$ & & \\
\hline \multirow[t]{2}{*}{ Mean number of hospital days during 3 months } & $C M$ & $12.67(11.93)$ & $12.62(10.62$ to 14.62$)$ & $3.75(0.79$ to 6.71$)$ & 0.013 \\
\hline & $\mathrm{ICHM}-\mathrm{ICH}$ & $8.75(10.47)$ & 8.87 (6.80 to 10.95$)$ & & \\
\hline \multirow[t]{2}{*}{ Mean number of hospital days during 1 year } & CM & $18.07(23.85)$ & 18.08 (14.41 to 21.73$)$ & $4.99(-0.43$ to 10.42$)$ & 0.071 \\
\hline & $\mathrm{ICHM}-\mathrm{ICH}$ & $12.98(15.47)$ & 13.08 (9.28 to 16.88$)$ & & \\
\hline \multirow[t]{2}{*}{ Mean length of hospital stay during 1 year (days) } & CM & $7.71(5.88)$ & $7.76(6.77$ to 8.75$)$ & 2.33 (0.86 to 3.80$)$ & 0.002 \\
\hline & $\mathrm{ICHM}-\mathrm{ICH}$ & $5.45(5.36)$ & 5.43 (4.41 to 6.46$)$ & & \\
\hline \multicolumn{6}{|l|}{ Total care days } \\
\hline \multirow{2}{*}{$\begin{array}{l}\text { Mean number of total days with institutional } \\
\text { care during } 1 \text { year }\end{array}$} & $C M$ & $32.40(44.05)$ & 34.58 (25.94 to 43.23 ) & $-0.50(-13.32$ to 12.32$)$ & 0.939 \\
\hline & $\mathrm{ICHM}-\mathrm{ICH}$ & $37.18(51.10)$ & 35.08 (26.11 to 44.06$)$ & & \\
\hline \multicolumn{6}{|l|}{ Use of primary health care } \\
\hline \multirow{2}{*}{$\begin{array}{l}\text { Mean number of hour-based primary health care } \\
\text { service during } 3 \text { months }\end{array}$} & $\mathrm{CM}$ & $25.72(56.60)$ & 30.61 (20.21 to 41.00$)$ & $0.34(-15.06$ to 15.74$)$ & 0.966 \\
\hline & $\mathrm{ICHM}-\mathrm{ICH}$ & $35.28(66.77)$ & 30.27 (19.48 to 41.05$)$ & & \\
\hline \multirow{2}{*}{$\begin{array}{l}\text { Mean number of hour-based primary health care } \\
\text { service during } 1 \text { year }\end{array}$} & $C M$ & $87.36(175.89)$ & 105.39 (71.55 to 139.24$)$ & $0.16(-50.01$ to 50.32$)$ & 0.995 \\
\hline & $\mathrm{ICHM}-\mathrm{ICH}$ & $123.79(247.55)$ & 105.24 (70.11 to 140.36$)$ & & \\
\hline \multirow{2}{*}{$\begin{array}{l}\text { Mean number of days in institutional primary health } \\
\text { care during } 3 \text { months }\end{array}$} & CM & $6.27(18.41)$ & 7.81 (5.08 to 10.53$)$ & $-2.16(-6.21$ to 1.88$)$ & 0.293 \\
\hline & $\mathrm{ICHM}-\mathrm{ICH}$ & $11.56(11.36)$ & 9.97 (7.14 to 12.80$)$ & & \\
\hline \multirow{2}{*}{$\begin{array}{l}\text { Mean number of days in institutional primary health } \\
\text { care during } 1 \text { year }\end{array}$} & $C M$ & $11.49(33.04)$ & 13.89 (6.89 to 20.89) & $-5.52(-15.89$ to 4.86$)$ & 0.296 \\
\hline & $\mathrm{ICHM}-\mathrm{ICH}$ & $21.87(43.24)$ & 19.40 (12.14 to 26.67$)$ & & \\
\hline \multirow[t]{2}{*}{ - Mean number of days in nursing home (long-term) } & CM & $1.80(13.15)$ & $2.02(-2.27$ to 6.31$)$ & $-3.10(-9.47$ to 3.26$)$ & 0.338 \\
\hline & $\mathrm{ICHM}-\mathrm{ICH}$ & $5.35(29.99)$ & 5.12 (0.67 to 9.58$)$ & & \\
\hline \multirow[t]{2}{*}{ - Mean number of days in $\mathrm{ICH}$} & $C M$ & $0.00(0.00)$ & $0.08(-1.39$ to 1.55$)$ & & \\
\hline & $\mathrm{ICHM}-\mathrm{ICH}$ & $12.95(11.25)$ & 12.86 (11.34 to 14.39$)$ & $-12.79(-14.96$ to -10.61$)$ & $<0.001$ \\
\hline \multicolumn{6}{|l|}{$\mathrm{ADL}^{\mathrm{c}}$} \\
\hline Mean functional status at 3 months & CM & $1.51(0.52)$ & $1.59(1.50$ to 1.67$)$ & $-0.05(-0.17$ to 0.07$)$ & 0.410 \\
\hline
\end{tabular}


Table 4 Post hoc analysis. Comparison of the ICHM-ICH group with the CM-group. Comparison of the ICHM-ICH with the $\mathrm{CM}_{\text {-group }}{ }^{\mathrm{a}}$ on use of health care services and functional status during one year after hospitalization for patients aged 60 years and older. (CM: 119 patients. ICHM-ICH: 110 patients) ${ }^{d}$ (Continued)

\begin{tabular}{|c|c|c|c|c|c|}
\hline & $\mathrm{ICHM}-\mathrm{ICH}$ & $1.72(0.55)$ & 1.64 (1.55 to 1.72$)$ & & \\
\hline \multirow[t]{2}{*}{ Mean functional status at 6 months } & CM & $1.52(0.56)$ & 1.57 (1.48 to 1.66$)$ & $-0.05(-0.19$ to 0.08$)$ & 0.444 \\
\hline & $\mathrm{ICHM}-\mathrm{ICH}$ & $1.69(0.53)$ & 1.63 (1.53 to 1.72$)$ & & \\
\hline
\end{tabular}

Analysis with ANCOVA adjusted for age, gender, number of diagnoses at index hospital stay, functional status at index hospital stay and having primary health care services at index hospital stay (yes/no)

${ }^{a}$ CM Comparative municipality, ICHM-ICH Patients in the ICHM discharged directly to the ICH (Intermediate care hospital)

${ }^{\mathrm{b}}$ Mean number of total days with institutional care = In-patient stays at hospital, primary health care, ICH and specialized rehabilitation

${ }^{\mathrm{C}} \mathrm{ADL}=$ Activities of daily living assessed with IPLOS (a national registration system with 17 ADL variables)

${ }^{\mathrm{d}}$ At index hospital stay patients with missing functional status were 1 in the $\mathrm{CM}$ and 0 in the ICHM-ICH. At 3 months the number of patients was six and three, respectively and at 6 months it was eight and 11

[34]. The ICH facilitated early hospital discharge for patients who were in need of further institutional care, reduced the pressure on hospital inpatient services and prevented prolonged hospital stays.

\section{Readmissions, mortality and activities of daily living}

Decreases in the length of hospital stay over the last decade [2] have raised concerns that early discharges may increase readmissions and mortality rates [44, 45]. This would imply that elderly people in the ICHM could be at risk because they were discharged earlier. In contrast to previous studies indicating that intermediate care may increase [26] or decrease readmissions [27], reduce mortality [24] or enable patients to regain abilities in daily living [19, 23], this study found no statistical significant differences between the municipalities. This was true for readmissions, mortality and ADL scores. These results alleviate the concern that the shorter length of hospitalizaton in elderly patients in a municipality with a discharge unit such as the ICH will lead to an increased risk of readmissions or deaths. This is supported by findings in other studies [46]. Indeed, a study of hospital discharges of patients aged 65 and older to skilled nursing facilities concluded that a 1-day reduction in length of hospital stay was not consistently associated with a higher rate of 30-day readmission [47].

\section{Strengths and limitations}

The strengths of this study were the inclusion of participants from two municipalities that were comparable on most baseline characteristics, the adjustment of the analyses for the differences in the groups, the collection of data from reliable electronic registers and the linkage of data on an individual level. The patients included in this study seem to be representative of all patients discharged to the ICH: For all patients from the ICHM aged 60 years and older who were discharged from the general hospital to the ICH from 2008 to 2011 [30], the average age was 79 years and $59 \%$ were female. In the present study, the average age was 78.2 years and $61.8 \%$ were female.
The major limitation was the study design, which was chosen because the ICH was already in operation. Hence, randomizing patients to the $\mathrm{ICH}$ or not was omitted due to both practical and ethical reasons. Additionally, we were interested in how the ICH operated within the primary health care service, i.e. the municipality level.

It should also be noted that the patients who lived alone were not registered and thus not adjusted for. Some patients could not consent due to their condition (e.g. strong analgesics or cognitive impairment). Moreover, the ICH model may be different in other settings which limits the generalizability. Cost analysis of alternative care models should be considered in future research.

\section{Conclusions}

The results show that patients from the municipality with access to an $\mathrm{ICH}$ used fewer hospital days and had a similar primary health care utilization among patients aged 60 years and older as patients from the municipality without an ICH. Having an ICH facilitated early hospital discharge for the patients and kept the risk of readmissions, mortality and the abilities to perform activities of daily living at the same level as without an $\mathrm{ICH}$.

\section{Abbreviations}

ADL: Activities of daily living; CM: Comparative municipality (Verdal municipality); ICH: Intermediate care hospital; ICHM: Intermediate care hospital municipality (Stjørdal municipality); ICHM-Home: The patients in the ICHM who were discharged directly to home; ICHM-ICH: The patients in the $\mathrm{ICHM}$ who were discharged directly to the $\mathrm{ICH}$.

\section{Competing interests}

The authors declare that they have no competing interests.

\section{Authors' contributions}

RJ and UD designed the study. UD collected the data, carried out the statistical analysis and wrote drafts of the manuscript. All authors participated in the analysis and critically revised and commented on the manuscript. All authors read and approved the final manuscript.

\section{Acknowledgements}

We would like to acknowledge all research study participants who have contributed to this study at the general hospital "Sykehuset Levanger", the 
university hospital "St. Olavs Hospital", the intermediate care hospital "DMS Værnesregionen" as well as primary health care services in Stjørdal and Verdal municipalities. We also thank Sveinung Aune for extracting the general hospital data.

The study was funded by the Central Norway Health Authority.

Received: 14 January 2015 Accepted: 24 August 2015 Published online: 28 August 2015

\section{References}

1. World Population Ageing 2013 [http://www.un.org/en/development/desa/ population/publications/pdf/ageing/WorldPopulationAgeingReport2013.pdf]

2. Health at a Glance: Europe 2012 [http://dx.doi.org/10.1787/9789264183896-en]

3. Counsell SR, Holder CM, Liebenauer LL, Palmer RM, Fortinsky RH, Kresevic $\mathrm{DM}$, et al. Effects of a multicomponent intervention on functional outcomes and process of care in hospitalized older patients: a randomized controlled trial of Acute Care for Elders (ACE) in a community hospital. J Am Geriatr Soc. 2000:48(12):1572-81.

4. Kosse NM, Dutmer AL, Dasenbrock L, Bauer JM, Lamoth CJ. Effectiveness and feasibility of early physical rehabilitation programs for geriatric hospitalized patients: a systematic review. BMC Geriatr. 2013;13:107.

5. Coleman EA, Fox PD. One patient, many places: managing health care transitions, Part I: introduction, accountability, information for patients in transition part one of a three-part series. Annals of Long Term Care. 2004;12:25-33.

6. Coleman EA, Fox PD. One patient, many places: managing health care transitions Part II: practitioner skills and patient and caregiver preparation. Annals of Long Term Care. 2004;12:34-9.

7. Mur-Veeman I, van Raak A, Paulus A. Comparing integrated care policy in Europe: does policy matter? Health Policy. 2008;85(2):172-83.

8. de Vries EN, Ramrattan MA, Smorenburg SM, Gouma DJ, Boermeester MA. The incidence and nature of in-hospital adverse events: a systematic review. Qual Saf Health Care. 2008;17(3):216-23.

9. Kripalani S, Jackson AT, Schnipper JL, Coleman EA. Promoting effective transitions of care at hospital discharge: a review of key issues for hospitalists. J Hosp Med. 2007;2(5):314-23.

10. Jasinarachchi KH, Ibrahim IR, Keegan BC, Mathialagan R, McGourty JC, Phillips JR, et al. Delayed transfer of care from NHS secondary care to primary care in England: its determinants, effect on hospital bed days, prevalence of acute medical conditions and deaths during delay, in older adults aged 65 years and over. BMC Geriatr. 2009:9:4.

11. Depalma G, Xu H, Covinsky KE, Craig BA, Stallard E, Thomas 3rd J, et al. Hospital readmission among older adults who return home with unmet need for ADL disability. Gerontologist. 2013;53(3):454-61.

12. Forster AJ, Clark HD, Menard A, Dupuis N, Chernish R, Chandok N, et al. Adverse events among medical patients after discharge from hospital. CMAJ. 2004;170(3):345-9.

13. Laugaland K, Aase K, Barach P. Interventions to improve patient safety in transitional care-a review of the evidence. Work. 2012;41 Suppl 1:2915-24.

14. Storm M, Groene O, Testad I, Dyrstad DN, Heskestad RN, Aase K. Quality and safety in the transitional care of the elderly (phase 2): the study protocol of a quasi-experimental intervention study for a cross-level educational programme. BMJ open. 2014;4(7):e005962.

15. Barnes DE, Mehta KM, Boscardin WJ, Fortinsky RH, Palmer RM, Kirby KA, et al. Prediction of recovery, dependence or death in elders who become disabled during hospitalization. J Gen Intern Med. 2013;28(2):261-8.

16. Young J. The development of intermediate care services in England. Arch Gerontol Geriatr. 2009:49 Suppl 2:S21-25.

17. National Service Framework for Older People. [https://www.gov.uk/government uploads/system/uploads/attachment_data/file/198033/National_Service_ Framework_for_Older_People.pdf]

18. Plochg T, Delnoij DM, van der Kruk TF, Janmaat TA, Klazinga NS. Intermediate care: for better or worse? Process evaluation of an intermediate care model between a university hospital and a residential home. BMC Health Serv Res. 2005:5:38.

19. Parsons M, Senior HE, Kerse N, Chen MH, Jacobs S, Vanderhoorn S, et al. The Assessment of Services Promoting Independence and Recovery in Elders Trial (ASPIRE): a pre-planned meta-analysis of three independent randomised controlled trial evaluations of ageing in place initiatives in New Zealand. Age Ageing. 2012;41(6):722-8.
20. Samhandlingsreformen. Rett behandling - på rett sted - til rett tid. St.meld.nr 47 (2008-2009). [The Coordination reform. Proper treatment - at the right place and right time. Report No. 47 to the Storting] [in Norwegian] [https://www.regjeringen.no/contentassets/d4f0e16ad32e4bbd8d8ab5c2144 $5 \mathrm{a} 5 \mathrm{dc} / \mathrm{no} / \mathrm{pdfs} / \mathrm{stm} 200820090047000 \mathrm{dddpdfs} . \mathrm{pdf}]$

21. Intermediate Care - Halfway Home [http://webarchive.nationalarchives.gov.uk/ 20130107105354/http://www.dh.gov.uk/prod_consum_dh/groups/ dh_digitalassets/@dh/@en/@pg/documents/digitalasset/dh_103154.pdf]

22. Melis RJ, Olde Rikkert MG, Parker SG, van Eijken MI. What is intermediate care? Br Med J (Clin Res Ed). 2004;329(7462):360-1.

23. Green J, Young J, Forster A, Mallinder K, Bogle S, Lowson K, et al. Effects of locality based community hospital care on independence in older people needing rehabilitation: randomised controlled trial. BMJ. 2005;331(7512):317-22.

24. Garasen $H$, Windspoll R, Johnsen R. Long-term patients' outcomes after intermediate care at a community hospital for elderly patients: 12-month follow-up of a randomized controlled trial. Scand J Public Health. 2008;36(2):197-204.

25. Garasen H, Windspoll R, Johnsen R. Intermediate care at a community hospital as an alternative to prolonged general hospital care for elderly patients: a randomised controlled trial. BMC Public Health. 2007;7:68.

26. Shepperd S, Doll H, Broad J, Gladman J, lliffe S, Langhorne P, et al. Early discharge hospital at home. Cochrane Database Syst Rev. 2009;1:CD000356.

27. Griffiths PD, Edwards MH, Forbes A, Harris RL, Ritchie G. Effectiveness of intermediate care in nursing-led in-patient units. Cochrane Database Syst Rev. 2007;2:CD002214.

28. Regen E, Martin G, Glasby J, Hewitt G, Nancarrow S, Parker H. Challenges, benefits and weaknesses of intermediate care: results from five UK case study sites. Health \& Social Care in the Community. 2008;16(6):629-37.

29. Young J, Gladman JR, Forsyth DR, Holditch C. The second national audit of intermediate care. Age Ageing. 2014;44:182-4. afu174.

30. Dahl U, Johnsen $R$, Saetre $R$, Steinsbekk $A$. The influence of an intermediate care hospital on health care utilization among elderly patients-a retrospective comparative cohort study. BMC Health Serv Res. 2015;15:48.

31. Des Jarlais DC, Lyles C, Crepaz N. Improving the reporting quality of nonrandomized evaluations of behavioral and public health interventions: the TREND statement. Am J Public Health. 2004;94(3):361-6.

32. Romoren TI, Torjesen DO, Landmark B. Promoting coordination in Norwegian health care. Int J Integr Care. 2011;11(Spec 10th Anniversary Ed):e127.

33. Styresak 30/2006. Videreføring av prosjekt "Distriktsmedisinsk senter i Stjørdalsregionen". [Board item no 30/2006. Follow-up project: "The intermediate care hospital in Stjørdal municipality"] [in Norwegian] [http://www.hnt.no/no/ Infosenter/Pressesenter/Styre/Styresaker-i-Helse-Nord-Trondelag-2006/Styresaker2006/30-2006-DMS-pa-Stjordal-avtaleinngaelse/66885/]

34. Dahl U, Steinsbekk A, Jenssen S, Johnsen R. Hospital discharge of elderly patients to primary health care, with and without an intermediate care hospital - a qualitative study of health professionals' experiences. Int J Integr Care. 2014;14:e011.

35. Information on the IPLOS-register [http://helsedirektoratet.no/Lists/Publikasjoner/ Attachments/10/Informasjon-om-iplos-registeret-IS-1441-engelsk.pdf]

36. Iplos registeret. Veileder for personell i kommunale helse- og omsorgstjenester [Iplos-register. Guide for personnel in municipal health and care services] [in Norwegian] [http://helsedirektoratet.no/retningslinjer/ iplos-veileder-for-personell-i-kommunale-helse-og-omsorgstjenester]

37. Dohl O, Garasen H, Kalseth J, Magnussen J. Variations in levels of care between nursing home patients in a public health care system. BMC Health Serv Res. 2014;14:108.

38. Dohl O, Garasen H, Kalseth J, Magnussen J: Factors associated with the amount of public home care received by elderly and intellectually disabled individuals in a large Norwegian municipality. Health Soc Care Community 2015. doi:10.1111/hsc.12209.

39. Statistikk banken. Folkemengd etter alder, kjønn, sivilstand og statsborgerskap. [Statistics Norway] [in Norwegian] [https://www.ssb.no/ statistikkbanken/selectvarval/Define.asp?subjectcode=\&Productld= $\&$ MainTable $=N Y 3026 \&$ nvl=\&PLanguage $=0 \&$ nyTmpVar=true\&CMSSubjectArea $=$ befolkning\&KortNavnWeb=folkemengde\&StatVariant=\&checked=true]

40. Yam CH, Wong EL, Chan FW, Wong FY, Leung MC, Yeoh EK. Measuring and preventing potentially avoidable hospital readmissions: a review of the literature. Hong Kong Med J. 2010;16(5):383-9.

41. Genindlæggelser af ældre i Danmark 2008. [Readmissions of elderly in Denmark 2008] [in Danish] [http://www.sst.dk/publ/Publ2009/DOKU/ nye_tal/Genindlaeggelser2008_final_m_bilag.pdf] 
42. Mur-Veeman I, Govers M. Buffer management to solve bed-blocking in the Netherlands 2000-2010. Cooperation from an integrated care chain perspective as a key success factor for managing patient flows. Int J Integr Care. 2011;11(Spec 10th Anniversary Ed):e080.

43. Johannessen AK, Luras $H$, Steihaug S. The role of an intermediate unit in a clinical pathway. Int J Integr Care. 2013;13:e012.

44. Heggestad T. Do hospital length of stay and staffing ratio affect elderly patients' risk of readmission? A nation-wide study of Norwegian hospitals. Health Serv Res. 2002;37(3):647-65.

45. Bueno H, Ross JS, Wang Y, Chen J, Vidan MT, Normand SL, et al. Trends in length of stay and short-term outcomes among Medicare patients hospitalized for heart failure, 1993-2006. JAMA. 2010;303(21):2141-7.

46. Brooke BS, Goodney PP, Powell RJ, Fillinger MF, Travis LL, Goodman DC, et al. Early discharge does not increase readmission or mortality after high-risk vascular surgery. J Vasc Surg. 2013;57(3):734-40.

47. Unruh MA, Trivedi AN, Grabowski DC, Mor V. Does reducing length of stay increase rehospitalization of medicare fee-for-service beneficiaries discharged to skilled nursing facilities? J Am Geriatr Soc. 2013;61(9):1443-8.

\section{Submit your next manuscript to BioMed Central and take full advantage of:}

- Convenient online submission

- Thorough peer review

- No space constraints or color figure charges

- Immediate publication on acceptance

- Inclusion in PubMed, CAS, Scopus and Google Scholar

- Research which is freely available for redistribution 